\title{
Comer Animais e Zoonoses: utilidade da pecuária industrial
}

\author{
Eating Animals and Zoonoses: usefulness of industrial livestock
}

\section{Larissa Lunkes Souza*}

Resumo: O objetivo central deste artigo é desenvolver a ideia sobre a utilidade ética da pecuária industrial com ênfase nas doenças zoonóticas a partir do referencial teórico de Peter Singer. Com o aumento da demanda em âmbito global por proteína animal, foram empreendidos novos métodos de manejo que submetem os animais a situações opostas ao bem-estar. Além do mais, essas mudanças são responsáveis pela ascensão das doenças zoonóticas. Desse modo, o presente trabalho trata-se da revisão bibliográfica dos livros Ética Prática e Libertação Animal do Peter Singer e artigos buscados nas plataformas: Scielo, Elsevier e Google Acadểmico. Assim, conclui-se que a pecuária industrial possui uma utilidade duvidosa dentro dos limites da pesquisa porque gera maior desprazer do que prazer.

Palavras-chave: Especismo; COVID-19; Ética; Saúde Pública; Utilitarismo

\begin{abstract}
The main objective of this article is to develop an ethical utility for industrial livestock with an emphasis on zoonotic diseases based on the theoretical framework Peter Singer. With the increase in the demand in the global scope of animal protein, new management methods have been developed that subject animals in situations opposite to well-being. In addition, these changes are responsible for the rise of zoonotic diseases. This is a bibliographic review of the books Practical Ethics and Animal Liberation by Peter Singer and articles searched on the platforms: Scielo, Elsevier and Google Scholar. Conclude that an industrial livestock has a utility within the limits of the research because it generates greater displeasure of pleasure.
\end{abstract}

Keywords: Speciesism; COVID-19; Ethics; Public Health; Utilitarianism

\section{Introdução}

O filósofo australiano nasceu no ano de 1946 e trabalha na perspectiva ética do utilitarismo de referências tendo como base uma formulação universal dos princípios éticos. Seu primeiro livro sobre ética animal, Libertação Animal de 1975, é reconhecido como precursor da inclusão dos animais não humanos na esfera da moralidade. A justificativa se detém na averiguação da sensciência, implicando atribuição aos interesses de bem-estar que incluem poder se locomover, conviver com sua prole, não passar por procedimentos que causem dor e viver conforme sua natureza. Porém, a pecuária industrial não reconhece esses interesses e, para manter os lucros e suprir uma alta demanda de proteína animal a baixo custo, submete animais a condições de vida miseráveis. Essa situação é preocupante, visto que esses métodos de produção de animais para o consumo alimentar humano é um dos agentes responsáveis pela transmissão e proliferação de patógenos. Estima-se que, nos últimos dez anos, três a cada quatro doenças bacterianas/virais são de origem ou derivadas de animais, entre elas, a família da corona vírus, que já resultou em três epidemias em menos de duas décadas: SARS, MERS-CoV e o atual COVID-19.

* Graduanda de Filosofia na Pontifícia Universidade Católica do Rio Grande do Sul, Porto Alegre, RS, E-mail: larissa.souza.003@acad.pucrs.br ORCID: $\underline{\text { https://orcid.org/0000-0001-7516-8017 }}$ 


\section{O Ético-Utilitário em Peter Singer}

Os principais pontos da teoria ética-utilitarista ${ }^{1}$ de Peter Singer são: 1) Consequencialismo, preocupação centralizada na consequência da ação, sendo ético o que é relativo à consequência, e não às "regras morais". 2) Formulação Universal, a qual considera todos os interesses dos afetados. 3) Princípio de igual consideração de interesses semelhantes, princípio da formula ética universal. 4) Reconhecimento da sensciência, fundamento para se ter interesses.

Consequencialismo, na perspectiva ético-utilitária, é uma ideia oposta à regra prescrita do que é o certo ou errado. Para os filósofos desta corrente, a ação ética é dependente do seu resultado. Por exemplo: a mentira não é certa nem errada em si; para saber se a mentira é moral será necessário submetê-las às consequências, analisando os interesses de todos os envolvidos. Logo, a ato de mentir não é certo nem errado, nem moral ou imoral, podendo ser ético ou não, pois depende intrinsicamente da situação problema. Além disso, existe o conceito de as "melhores consequências" como: "A forma de pensar que esbocei é uma forma de utilitarismo. Difere do utilitarismo clássico no facto de 'melhores consequências' ser entendido como aquilo que, ponderadas as alternativas, aprofunda os interesses dos afectados, e não meramente o que aumenta o prazer e reduz o sofrimento",

A consequência da ação possui utilidade, sendo esta o resultado das análises e ponderamentos sobre os interesses dos seres, de forma que se guie a partir dos princípios, por exemplo, da igual consideração de interesses semelhantes. A utilidade da ação é a análise neutra e será positiva quando abranger mais princípios. Em vista disso, a utilidade é uma forma de "matematizar" os juízos morais e, quando a ação possui mais princípios e/ou gera mais prazer, significa que está potencializando a utilidade, caso contrário, minimizando. Peter Singer define: “Termos como 'prazer' e 'felicidade': são pouco precisos, mas não restam dúvidas de que se referem a algo que se sente ou se vive; por outras palavras, a estados de consciência" 3 . Percebe-se que o prazer é insuficiente para definir a utilidade porque, em sua perspectiva, não aprofunda as alternativas.

A ação, para ser considerada moral, precisa seguir uma formulação universal, pois, caso contrário, compromete a validade ética, significando que todos os interesses de todos os seres envolvidos devem ser encarados. Diante disso, a consideração do interesse de outrem deve possuir a mesma medida do interesse pessoal, senão o sujeito pode afirmar que a ação maximizou o prazer e minimizou o desprazer, porém a resposta "maximizou" é altamente duvidosa porque não analisou todos os interesses, podendo ter gerado mais desprazer. "[...] Ao aceitar que os juízos éticos devem ser formulados de um ponto de vista universal, estou a aceitar que os meus próprios interesses, só porque são os meus interesses pessoais, não podem contar mais do que os interesses de qualquer outra pessoa" $"$.

A formulação ética universal é a igual consideração de interesses semelhantes. Se o interesse é $\mathrm{x}$, todos os seres que possuírem esse interesse devem ser levados em consideração com a mesma importância. Esse critério garante que a consequência na sua universalidade maximizará o prazer

\footnotetext{
${ }^{1} \mathrm{O}$ utilitarismo é uma perspectiva da ética. O percursor dessa teoria, que influenciou severamente Singer, é Jeremy Bentham (1748-1832) criando o utilitarismo clássico. Em todas formas de utilitarismo o enfoque será na consequência, recebeu grande influencia no empirismo de David Hume e do hedonismo, por isso, o objetivo da ética utilitarista é considerar a ação moral a que maximiza o prazer (de todos envolvidos) e com minimiza o desprazer.

${ }^{22}$ SINGER, Practical Ethics, 14. Tradução do autor: "The way of thinking I have outlined is a form of utilitarianism. It differs from classical utilitarianism in that 'best consequences' is understood as meaning what, on balance, furthers the interests of those affected, rather than merely what increases pleasure and reduces pain".

${ }^{33}$ SINGER, Practical Ethics, 90. Tradução do autor: “Terms like 'pleasure' and 'happiness' lack precision, but it is clear that they refer to something that is experienced, or felt - in other words, to states of consciousness".

${ }^{4}$ SINGER, Practical Ethics, 12. Tradução do autor: "In accepting that ethical judgments must be made from a universal point of view, I am accepting that my own interests cannot, simply because they are my interests, count more than the interests of anyone else".
} 
para a situação macro dos envolvidos da ação. O afeto, apego e afinidade, não tornam o interesse mais relevante ou com maior valor moral ${ }^{5}$.

A formulação descreve: "igual consideração para interesses semelhantes". Todavia, o que significa ser igual? A igualdade é inicialmente uma ideia moral oposta a uma perspectiva homogênea das pessoas, e também de igualdade efetiva, de que se vale para um indivíduo necessariamente serve para o outro. Ou seja, não é a negação da individualidade e nem é redução dos seres as suas especificidades. Igualdade significa considerar seres iguais reconhecendo suas diferenças e que suas reivindicações de direitos se referem às suas capacidades que se manifestam em interesses. Logo, refere-se à igual consideração dos interesses semelhantes 'respeitando' suas diferenças e capacidades: “(...) O princípio da igualdade dos seres humanos não é a descrição de uma suposta igualdade de fato existente entre seres humanos: é a prescrição de como devemos tratar os seres humanos"6.

A prescrição com que deve-se tratar os seres humanos e de considerar as suas capacidades, que se desdobram em interesses, no sentido de considerar que as capacidades do ser definem seus interesses e, com isso, o que devem possuir como direito ético, por exemplo: os animais têm a capacidade de sentir dor, eles possuem o interesse em não senti-la. Todavia, os animais não têm capacidade de estudar, logo não possuem esse interesse. O princípio da igualdade diz que é preciso ser reconhecido esse interesse do animal em não querer sentir dor, e não o direito à escola aos animais, simplesmente porque o direito se vincula ao interesse desse ser.

Para o autor em questão, a igualdade das considerações de interesses semelhantes é o único critério admissível para uma perspectiva ética, pois, se o critério for baseado na aparência, inteligência, linguagem, cor, gênero, entre outros, ele será arbitrário. Também, fomentam-se as considerações de interesses porque a capacidade pode ser negada e usada para oprimir. Por exemplo: se utilizarmos o teste de QI para medir a inteligência, quem tem a capacidade de ser mais inteligente deve ter mais direito a educação? Para Singer, não, porque as pessoas que forem mal no teste de QI possuem a capacidade de aprender e têm esse interesse. O fato de o outro ter essa capacidade de "forma melhorada" não muda o fato de que o sujeito tem esse interesse e que esse direito deve ser reconhecido dentro de sua perspectiva de igualdade moral ${ }^{7}$.

$\mathrm{Na}$ opinião de Peter Singer, a raiz do racismo e do sexismo é o não reconhecimento igualitário dos interesses semelhantes desses grupos, ou seja, é um preconceito baseado numa característica arbitrária, respectivamente de cor e de gênero. Ele traça a analogia com essas opressões porque para ele o especismo possui a mesma raiz. Definindo-o como: “[...] Especismo é o preconceito ou a atitude tendenciosa de alguém a favor dos interesses de membros de sua própria espécie e contra os de outras" ". Significa que a pessoa especista tolera, com outras espécies, "coisas" que não toleraria com a sua, unicamente com a argumentação de que é de outra espécie e que não existe problema. É evidente que a espécie, em alguns momentos, será fronteira justamente por causa das diferenças, mas existem diferenças que, nesse caso, referem-se à utilidade de serem minimizada, não por serem de outra espécie.

O que seria o interesse de um animal não humano? Em Singer, a primeira capacidade animal a ser reconhecida é a sensciência, já que é a condição biológica de ser capaz de sentir dor, prazer e desprazer. É sabido que os animais vertebrados, principalmente aves e mamíferos, são portadores de sensciência. Para tal filósofo, essa capacidade é o único limite defensável para atribuição de status moral, pois: “[...] caso um ser não seja capaz de sofrer, de sentir prazer ou felicidade, nada há a ser levado em conta. Portanto, o limite da sensciência é a única fronteira defensável de consideração dos interesses alheios",.

Assim, o reconhecimento da sensciência do animal não humano é importante porque coloca os animais como seres capazes de possuir interesses, sendo estes relativos à sensciência. Desse

\footnotetext{
${ }^{5} \mathrm{O}$ afeto, apego e afinidade não tornam o interesse de y mais significativo do que o interesse semelhante de $\mathrm{x}$. Mas, pode ser considerado como outro interesse que se soma.

${ }^{6}$ SINGER, Libertação Animal, 6.

${ }^{7}$ SINGER, Libertação Animal, 5.

${ }^{8}$ SINGER, Libertação Animal, 8.

${ }^{9}$ SINGER, Libertação Animal, 10.
} 
modo, os animais, por conta dessa capacidade, possuem o interesse em viver sua vida com bemestar, como: alimentar-se, locomover-se, viver conforme sua natureza, relacionar-se com membros da sua espécie, dentre outros que se relacionam com a capacidade de sentir. O interesse localiza-se no bem-estar porque: "[...] a dor e o sofrimento são maus e devem ser evitados ou minimizados, independentemente da raça, sexo ou espécie do ser que os sofrem"10.

Em prol de questionar sobre o consumo de animais não humanos na alimentação, o autor em evidência menciona: 1) Consumo de carne animal para sobrevivência. 2) Nas cidades industrializadas animais são comidos por luxo. 3) Animais condicionados em situações miseráveis para diminuição do custo. 4) Garantia de não dor. 5) 'Existência Prévia', sendo importante ressaltar que os ditos animais de consumo são considerados como senscientes. Dessa forma, dentro da teoria de Peter Singer é necessário considerar seus interesses de bem-estar, mas por não se saber se são pessoas $^{11}$, não pode ser atribuído interesse em continuar vivendo.

No primeiro caso, o respectivo filósofo considera lugares não urbanizados onde existem problemas no acesso de alimentos não animal. O exemplo utilizado é dos Esquimós que consomem carne pela sobrevivência, alegando ser "moralmente mais importante que as pessoas se alimentem e possam sobreviver, do que preservar a vida de um animal unicamente sensciente". No caso de sobrevivência, existe justificativa em Singer porque as pessoas possuem mais capacidades e interesses. Desse modo, é utilitário salvar a vida da pessoa e não a do animal e mesmo que o animal seja o prejudicado, nesse caso, não é um caso de especismo, pois a decisão para isso não foi especista de "por ser de outra espécie", mas sim pelos interesses dos seres. Mas a maioria das pessoas não pode utilizar desse argumento, pois seu consumo não é relacionado com a sobrevivência ${ }^{12}$.

A maior parte do consumo de carne animal e derivados ocorre nas cidades industrializadas. Conforme o autor ${ }^{13}$ em estudo, o primeiro contato dessas pessoas com os animais é nas refeições. Porém, no mesmo lugar onde se adquirem esses produtos, encontra-se outros. Os mercados vendem tanto as carnes, leites, ovos como também legumes, verduras e grãos (base de uma alimentação vegetariana). $\mathrm{Na}$ atualidade, existem vários órgãos de saúde que apontam a dieta vegetariana como saudável. Esses fatos justificam a afirmação de Singer: “[...] os animais não são comidos por motivos de saúde nem para aumentar a nossa quantidade disponível de alimentos. A sua carne é consumida como um luxo, porque as pessoas apreciam o seu sabor"14.

$\mathrm{Na}$ pecuária industrial, existem diversos maus-tratos aos animais de consumo. Alguns métodos utilizados são: ausência de espaço para locomoção, gaiolas inadequadas (tamanho, forragem que machuca os pés), debicagem, marcação, inseminação artificial, negação do convívio com a prole, retirada do rabo e castração sem anestesias. Os animais não humanos que são utilizados para o consumo alimentar humano são postos em condições de vida miseráveis para a redução dos custos da produção ${ }^{15}$. Assim, as pessoas conseguem ter o prazer do gosto e da textura do corpo animal a um preço acessível sendo o este a infração do interesse de maior qualidade, o bem-estar dos animais. Por isso, os "produtos" oriundos da pecuária industrial não devem ser consumidos. "[...] para evitar o especismo temos de pôr fim a essas práticas. A nossa prática

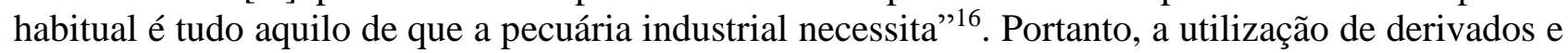
do corpo de animais não tem como ser ética quando originária dessas indústrias.

\footnotetext{
${ }^{10}$ SINGER, Practical Ethics, 61. Tradução do autor: "Pain and suffering are bad and should be prevented or minimised, irrespective of the race, sex, or species of the being that suffers".

${ }^{11}$ SINGER, Practical Ethics,110. Expõe animais que são pessoas, principalmente chimpanzés e gorilas (são os exemplos que ele discorre mais sobre), porque eles possuem capacidades de auto reconhecimento, linguagem e aprendizagem. Ele afirma também que os “ditos animais somente senscientes” é uma presunção e não uma certeza.

12 SINGER, Practical Ethics, 62.

13 SINGER, Practical Ethics, 62.

${ }^{14}$ SINGER, Practical Ethics, 63. Tradução do autor: “(...) animals are eaten neither for health, nor to increase our food supply. Their flesh is a luxury, consumed because people like its taste".

15 SINGER, Libertação Animal, 108-177.

${ }^{16}$ SINGER, Practical Ethics, 63. Tradução do autor: "To avoid speciesism we must stop these practices. Our custom is all the support that factory farmers need".
} 
Na perspectiva do utilitarismo total do filósofo Leslie Stephen, é negado o direito à vida aos animais somente senscientes, e estes são definidos como "receptores de sensações". Assim, a vida dos animais só é valiosa quando proporciona experiências valiosas como o prazer. Logo, tal ideia significa afirmar que as únicas coisas que importam em relação aos animais é o bem-estar e que ao tirar-lhe vida para dar a vida a outro animal, haveria um saldo positivo. Tirar-se-ia a vida deste animal para o consumo do seu corpo e se criaria outro no lugar para a mesma finalidade, sendo este "argumento da substituição". Singer responde a essa afirmação no livro Ética Prática ${ }^{17}$, concordando com o argumento (dentro da perspectiva do utilitarismo total), uma vez que traz a ressalva de que, na indústria, a condição de vida do animal não é de bem-estar, assim invalidando o argumento. Se a vida desses animais não é de prazer, é uma impossibilidade causar saldo positivo e "ser bom" existir outro animal que vá desfrutar dessa vida. Então, o argumento da substituição só seria válido se outro animal fosse desfrutar da vida com bem-estar para 'substituir'. A substituição, no contexto da pecuária industrial atual, causa uma maximização do desprazer.

Se aceito o pensamento de Leslie Stephen, o mesmo só é justificável ao ter-se certeza que esse animal pôde desfrutar da sua vida com bem-estar e que a morte dele foi indolor. Consequentemente seria possível consumir: os ovos de galinhas livres, o leite que sobra do consumo do bezerro, entre outros pouquíssimos exemplos. Sobre a questão de a morte ser indolor, Singer afirma que muitos processos não provocam morte instantânea (pode ser citado à sangria do abate artesanal) e o animal continua sofrendo. Além disso, "existe também o efeito da morte do animal no companheiro ou companheira ou em outros membros do grupo social do animal. Há muitas espécies de aves nas quais a ligação entre macho e fêmea dura toda a vida" 18 .

A convicção de Singer é a da perspectiva utilitarista que atribui aos animais não humanos o sstatus de "existência prévia", entendendo como um 'mal'/'desprazer' tirar a vida do que poderia ter uma vida mais alongada. Essa perspectiva considera que é errado matar um animal para alimentação (a não ser que seja para a sobrevivência), simplesmente porque a vida de um animal possui maior qualidade de prazer do que o prazer em comê-los: "Esta perspectiva implica que é normalmente um mal matar animais para a alimentação, visto que poderíamos fazer esses animais terem alguns meses ou mesmo anos agradáveis antes de morrerem -- e o prazer que obtemos ao comê-los não tem maior peso do que isso"19.

Cessando esta seção, o consumo de animais só pode ser entendido de modo moral dentro do utilitarismo total que considera os animais somente como senscientes e que essa capacidade não os confere status de direito à vida, o consumo torna-se tolerável no argumento da substituição. Também, nos casos de sobrevivência, o interesse da pessoa em se manter viva sobrepõe ao do animal não humano. Singer afirma que o consumo não é moral quando: não existe certeza de que o animal obteve uma vida de bem-estar e uma morte indolor, quando se segue a perspectiva da existência prévia ou quando a fundamentação for especista.

\section{Doenças Zoonóticas e Pecuária Industrial}

Essa relação que nós humanos possuímos com os animais não humanos, especialmente na alimentação, tem que ser vista além da ótica moral da utilização dos animais (já explicitada anteriormente), mas também na perspectiva da saúde pública. Infere-se isso por causa de: “[...] animais podem ser fonte de doenças infecciosas causadas por vírus, bactérias e parasitas, que podem ser transmitidas para a população humana ${ }^{20}$. Essas doenças são denominadas zoonoses" ${ }^{21}$.

\footnotetext{
${ }^{17}$ SINGER, Practical Ethics, 121-123.

${ }^{18}$ SINGER, Practical Ethics, 120. Tradução do autor: "There is also the effect of the death of one animal on his or her mate or other members of the animal's social group. There are many species of birds in which the bond between male and female lasts for a lifetime".

${ }^{19}$ SINGER, Practical Ethics, 120. Tradução do autor: "This view implies that it is normally wrong to kill animals for food, since usually we could bring it about that these animals had a few pleasant months or even years before they died - and the pleasure we get from eating them would not outweigh this".

${ }^{20}$ SEIMENIS apud ZANELLA, Zoonoses emergentes e reemergentes e sua importância para saúde e produção animal.
} 
É curioso balancear que predominantemente os humanos se alimentam de animais e os utilizam no entretenimento, na domesticação, e nos transportes, ao passo que essa mesma relação compromete a saúde humana, sistematicamente levando à óbito: "aproximadamente $75 \%$ das doenças infeciosas emergentes que impactam ou ameaçam a saúde dos humanos são Zoonóticas" 22 . Ademais, estima-se que, nos últimos dez anos, três a cada quatro patógenos emergentes são de origem animal de derivados ${ }^{23}$, como: gripe bubônica, espanhola e suína ${ }^{24}$, BSE, brucelose, campilobacteriose, salmonelose, listeriose ${ }^{25}$.

Conforme a doutora infectologista Tânica $\mathrm{Cruz}^{26}$, em menos de duas décadas, a humanidade está passando pela terceira epidemia: o coronavírus, enfermidade de elevada transmissibilidade. A primeira, cronologicamente: foi a síndrome aguda grave (SARS), começada em Guangdong Province, China em 2002-2003, espalhando-se por "[...] 30 países em 6 continentes e resultou em 8098 casos cumulativos e 774 mortes" ${ }^{27}$. Síndrome respiratória aguda do Oriente Médio (MERSCoV), a qual teve início em 2012, “[...] confinada na península arábica, responsável por 2494 casos com 858 óbitos. A Coreia do Sul registrou a ocorrência do MERS-COV e neste surto foram registradas 38 mortes" 28 . Por último, a atual é pandemia do SARS-COV-2 (COVID-19), começada em dezembro de 2019, na cidade de Wuhan na China ${ }^{29}$.

A SARS, MERS-CoV e o Covid-19 são consequências do genoma $\mathrm{CoV}$, que é um vírus de RNA. Assim, tais vírus possuem capacidade de sofrer diversas mutações e incorporar em seu genoma. Quando inseridos na ótica evolutiva, ocorrem adaptações com os vírus citados que possibilitam transmissão inter-humana ${ }^{30}$. Conforme a Janice R.C.Zanella ${ }^{31}$, são diversos fatores que proporcionam um aumento da proliferação dos vírus zoonóticos, sendo os fatores de risco: aumento da população humana, industrialização e segurança de alimento, transportes de pessoas ou animais doentes, turismo e globalização, domesticação e interação com animais silvestres, mudanças climáticas e uso do solo, adaptação do patógeno à nova espécie hospedeira, aquisição de novos fatores de virulência, produção animal e alteração das práticas de manejo, animais de companhia, carnes de caça, contato com animais de estimação, de zoológico e de circo ${ }^{32}$.

A produção animal e as práticas de manejo são apontadas como fatores de risco para o surgimento de doenças zoonóticas emergentes. O primeiro motivo aponta a pecuária como transportadora de patógenos, uma vez que os animais confinados na indústria pecuária compõem um ecossistema único, sendo este a integração entre humanos, animais de consumo e selvagens e patógenos, tudo isso imerso num ambiente antropomorficamente projetado para ampliação de lucros em detrimento da sustentabilidade biológica, consolidando o fato de que o animal criado para o

\footnotetext{
${ }^{21}$ BROWN apud ZANELLA, Zoonoses emergentes e reemergentes e sua importância para saúde e produção animal.

22 EIDs apud LEIBLER et al, Industrial Food Animal Production and Global Health Risks: Exploring the Ecosystems and Economics of Avian Influenza, 278. Tradução do autor: "Nearly 75\% of all emerging infectious diseases (EIDs) that impact or threaten human health are zoonotic".

23 TAYLOR apud LEIBLER et al, Industrial Food Animal Production and Global Health Risks: Exploring the Ecosystems and Economics of Avian Influenza, 59.

${ }^{24}$ ZANELLA, Zoonoses emergentes e reemergentes e sua importância para saúde e produção animal.

${ }^{25}$ FRAZÃO MATEUS, Animais à Mesa: Zoonoses e Estratégias no Consumo da Carne, 1.

${ }^{26}$ CHAVES; BELLEI, SARS-COV-2, o novo Coronavírus: uma reflexão sobre a Saúde Única (One Health) a importância da medicina de viagem na emergência de novos patógenos.

${ }^{27}$ AL-TAWFIQ; ZUMLA; MEMISH, Travel implication of emerging coronaviruses: SARS and MERS-CoV, 423. Tradução do autor: "30 countries in 6 continents and resulted in a cumulative 8098 cases and 774 deaths"

${ }_{28}$ MUNSTER apud CHAVES; BELLEI, SARS-COV-2, o novo Coronavírus: uma reflexão sobre a Saúde Única (One Health) a importância da medicina de viagem na emergência de novos patógenos.

${ }^{29}$ CHAVES; BELLEI, SARS-COV-2, o novo Coronavírus: uma reflexão sobre a Saúde Única (One Health) a importância da medicina de viagem na emergência de novos patógenos

30 CHAVES; BELLEI, SARS-COV-2, o novo Coronavírus: uma reflexão sobre a Saúde Única (One Health) a importância da medicina de viagem na emergência de novos patógenos

31 Ph.D em Virologia Molecular pela Universidade de Nebraska, EUA. https://www.embrapa.br/equipe/lempregado/296824/janice-reis-ciacci-zanella

32 ZANELLA, Zoonoses emergentes e reemergentes e sua importância para saúde e produção animal. Grifo do autor.
} 
consumo alimentar assume a posição de ser o vetor (por ser hospedeiro) das transferências de patógenos dos animais silvestres para a população humana ${ }^{33}$.

Igualmente, pesquisadores da zoonose cryptpsporidiosis analisaram mapas digitais das fronteiras da planície de inundação que é usada na operação do gado durante o período de 100 $\operatorname{anos}^{34}$. Eles asseguram o seguinte parecer: "As fazendas de gado representam fontes pontuais de contaminação ambiental com C. parvum se as práticas de manejo na fazenda falharem em minimizar o transporte de patógenos do esterco bovino para as águas superficiais adjacentes" 35 .

O segundo motivo é a hipótese de que os animais, ao serem vetores de patógenos, desenvolvem um ambiente favorável para que eles se tornem resistentes. Isso ocorre porque a alimentação dos animais de consumo é formulada com agentes antimicrobianos, a fim de aumentar o crescimento dos animais e de antibióticos para a segurança da carne animal ou do derivado. Desse modo, os patógenos, por estarem expostos com frequência a esses 'medicamentos', desenvolvem resistência a eles ${ }^{36}$. Indica-se que a alimentação formulada é substancialmente diferente dos alimentos tradicionais da espécie ${ }^{37}$.

O aumento da população mundial e o maior acesso econômico em países como a China geraram maior demanda por proteína animal. Com isso, a pecuária industrial aderiu a novos métodos, garantindo uma alta produção, e empreendeu procedimentos como: rápida rotação, agilização máxima para transformar o animal no produto alimentar, superlotação (auxilia na proliferação dos patógenos por causa do maior contato), confinamento, onde os animais ficam num determinado espaço físico (que não é o suficiente para um bem-estar do animal). Há também a formulação da alimentação já citada, que é fundamental para poder ser viável uma rotação ágil já que os agentes antimicrobianos para o crescimento é o que fazem o animal conseguir um tamanho satisfatório num curto espaço de tempo ${ }^{38}$.

O aumento da demanda por proteína animal e instalações de novos métodos de manejo, principalmente por causa da alta rotatividade e confinamento, resulta em grande quantidade de dejetos, chegando a 314 milhões de toneladas por ano somente nos Estados Unidos. Todo esse resíduo que contém alta quantidade de patógenos é colocado sem nenhum preparo com na terra ${ }^{39}$.

Além dos dejetos, o desmatamento de áreas naturais para a produção de animais de consumo alimentar se dá como necessária. Esse processo ocorre atualmente com a Amazônia e é principal problema, tendo como consequência a agricultura de larga escala, a produção de soja, a qual está intimamente interligada com a pecuária brasileira $)^{40}$. Segundo pesquisadores, o desmatamento da área natural para a ampliação da pecuária é um dos fatores que favorecem a transmissão de zoonoses:

O avanço da agricultura e da pecuária próximo às áreas naturais proporcionou um contato entre as populações humanas e de seus animais domésticos com as populações de animais silvestres nos seus habitats. Este estreito contato facilitou a

\footnotetext{
${ }^{33}$ LEIBLER et al, Industrial Food Animal Production and Global Health Risks: Exploring the Ecosystems and Economics of Avian Influenza, 59.

${ }^{34}$ GRACZYK et al. Environmental and Geographical Factors Contributing to Watershed Contamination with Cryptosporidium parvum Oocysts.

${ }^{35}$ GRACZYK et al apud GRACZYK et al , Ecology of Zoonotic Cryptosporidiosis in WatershedsContaining Cattle Farming Operations, 200. Tradução nossa: "Cattle farms represent point sources of environmental contamination with C. parvum if on-farm management practices fail to minimize pathogen transport from bovine manure to adjacent surface water"

${ }^{36}$ GAZE et al apud LEIBLER et al, Industrial Food Animal Production and Global Health Risks: Exploring the Ecosystems and Economics of Avian Influenza, 59.

${ }^{37}$ SAPKOTA et al apud LEIBLER et al, Industrial Food Animal Production and Global Health Risks: Exploring the Ecosystems and Economics of Avian Influenza, 60.

${ }^{38}$ LEIBLER et al, Industrial Food Animal Production and Global Health Risks: Exploring the Ecosystems and Economics of Avian Influenza, 60.

${ }^{39}$ ZHENG apud LEIBLER et al, Industrial Food Animal Production and Global Health Risks: Exploring the Ecosytems and Economics of Avian Influenza, 61.

40 RIVEIRO et al, Pecuária e desmatamento: uma análise das principais causas diretas do desmatamento na Amazônia.
} 
disseminação de agentes infecciosos e parasitários para novos hospedeiros e ambientes, estabelecendo-se assim novas relações entre hospedeiros e parasitas, e novos os nichos ecológicos na cadeia de transmissão das doenças ${ }^{41}$.

\section{Utilidade da Pecuária Industrial}

Os livros analisados de Peter Singer não previam as implicações morais das doenças zoonóticas. Por essa razão, o objetivo desta seção é correlacionar as evidências cientificas em relação à pecuária e a proliferação dos patógenos, junto com as críticas do autor em questão sobre esta indústria. Os tópicos são respectivamente: 1) Alta demanda por proteína animal; 2) Baixo custo da produção; 3 ) Manejo dos animais não humanos.

Conforme demonstrado na seção anterior, a demanda por carne animal está em crescimento devido ao aumento populacional em âmbito global e à ascensão econômica de alguns países ${ }^{42}$. Contudo, Singer irá demonstrar que grande parte do consumo de alimentos de origem animal se dá nos centros urbanos e que essas refeições são o primeiro contato interespécies. Conjuntamente, o autor alega que os órgãos de saúde asseguram que a dieta vegetariana pode ser saudável. Por essas razões, Singer afirma que os consumidores das cidades urbanas consomem carne e derivados pelo prazer com a textura/gosto, e não por necessidade ou sobrevivência ${ }^{43}$.

Ademais, Singer acusa a pecuária industrial como o principal problema relacionado ao consumo alimentar de animais não humanos, justamente porque eles são submetidos a condições miseráveis pela finalidade de consumi-los a baixo custo ${ }^{44}$. Assim, o consumo de carne animal e derivados dentro dessa ótica sem bem-estar é um ato especista, já que desconsidera os interesses dos animais a partir da arbitrariedade da espécie ${ }^{45}$. Os pesquisadores expõem esse problema através do prisma financeiro: "[...] a produção animal de alimentos também é inerentemente a uma atividade econômica, impulsionada por incentivos financeiros e motivos de lucro. Essas forças econômicas existem paralelamente às pressões biológicas que moderam a evolução e a propagação de patógenos"46. É válido resgatar a informação de que a pecuária industrial, ao não buscar uma sustentabilidade de produção, constrói um ecossistema propício para proliferação dos patógenos emergentes.

O terceiro motivo é uma consequência de ambos os processos correlacionados. Com o objetivo de a produção ser em alta escala com baixo custo e gerando lucro, a pecuária industrial ignora os interesses de bem-estar dos animais não humanos. Os métodos utilizados pela indústria pecuária são: rápida rotação, confinamento e alimentação formulada ${ }^{47}$. Estes métodos garantem respectivamente alta produção, economia, aceleração do crescimento para existir alta rotatividade e resolução médica para consequências do confinamento. Peter Singer, no terceiro capítulo, descreve diversos procedimentos contrários ao bem-estar animal na indústria. A maioria deles é para viabilizar o confinamento desses animais. Como exemplo, temos a: debicagem, processo em que retiram os bicos das aves, dado que o confinamento impõe situação de estresse extremo a ponto de

\footnotetext{
${ }^{41}$ CORRÊA; PASSO apud RIVEIRO et al, Pecuária e desmatamento: uma análise das principais causas diretas do desmatamento na Amazônia,1.

${ }^{42}$ LEIBLER et al, Industrial Food Animal Production and Global Health Risks: Exploring the Ecosystems and Economics of Avian Influenza, 60.

${ }^{43}$ SINGER, Practical Ethics, 63.

${ }^{44} \mathrm{O}$ custo da carne e de seus derivados não é necessariamente barato. A questão que o autor tenta trabalhar com "baixo custo" é que, caso se garantisse o bem estar animal dentro da pecuária industrial o preço se elevaria radicalmente.

${ }^{45}$ SINGER, Libertação Animal, 8.

${ }^{46}$ LEIBLER et al, Industrial Food Animal Production and Global Health Risks: Exploring the Ecosystems and Economics of Avian Influenza,68. Tradução do autor: "However, food animal production is also inherently an economic activity, driven by financial incentives and profit motives. These economic forces exist in parallel with the biological pressures that moderate pathogen evolution and spread".

47 LEIBLER et al, Industrial Food Animal Production and Global Health Risks: Exploring the Ecosystems and Economics of Avian Influenza, 60.
} 
machucarem umas as outras, e a retirada do rabo - sem anestesia, cortam os rabos dos porcos, visto que, na condição de ausência de entretenimento e espaço, eles mordem a calda um do outro ${ }^{48}$.

Singer, inserido em seu utilitarismo das preferências que aprofunda os interesses dos afetados e pondera as alternativas, considera que, com exceção às situações de sobrevivência e de necessidade, o consumo de carne animal não é ético, justamente por seu princípio de existência prévia atribuir como um mal/desprazer matar animais que poderiam desfrutar por mais tempo de sua vida e por afirmar que agradar o paladar é um prazer com menor relevância ${ }^{49}$. Com relação à perspectiva do utilitarismo total, concluindo que o "argumento da substituição", este argumento só será válido mediante a certeza da vida animal com bem-estar. O bem-estar inclui que o animal possa locomover-se, ter contato com sua prole, não ser submetido a procedimentos que sofra e que possa viver conforme a própria natureza ${ }^{50}$. Então, tirando os casos de necessidade e sobrevivência, não é moral o consumo de animais oriundos da indústria pecuária.

Além disso, a pecuária industrial atual é responsável por ser um dos agentes que propiciam a proliferação de patógenos emergentes, desse modo cooperando para problemas de epidemias: "aproximadamente $75 \%$ das doenças infeciosas emergentes que impactam ou ameaçam a saúde dos humanos são Zoonóticas" 51 , prejudicando a saúde pública. Ademais, tal setor não reconhece os interesses dos animais, infringindo seu bem-estar. Em razão desses fatores, é viável concluir que a utilidade da indústria pecuária só será positiva quando diminuir a demanda que resulte a não necessidade de métodos como alta rotação, confinamento e alimentação formulada. É mutuamente imprescindível que seja exigido que as indústrias pecuárias tenham obrigação em garantir bem-estar aos animais porque o bem-estar é um direito deles "e os direitos não podem ser cerceados pelas preferências nem pelo prazer dos outros" $" 52$.

\section{Referências}

AL-TAWFIQ, J. A.; ZUMLA, A. Travel implications of emerging coronaviruses: SARS and MERS-CoV. Travel Medicine and Infectious Disease, v. 12, n. 5, p. 422-428, 2014. Disponível em: https://www.ncbi.nlm.nih.gov/pubmed/25047726 Acesso em: 14 abril 2020.

CHAVES, T.; BELLEI, N. SARS-COV-2, o novo Coronavírus: uma reflexão sobre a Saúde Única (One Health) e a importância da medicina de viagem na emergência de novos patógenos. Revista de Medicina, v. 99, n.1, p. 0-3, 2020. Disponível em: http://www.revistas.usp.br/revistadc/article/view/167173 Acesso em: 14 abril 2020.

EVANS, B. M., GRACZYK, T. K.., SHIFF, C. J., KARREMAN, H. J., PATZ, J. A. Environmental and Geographical Factors Contributing to Watershed Contamination with Cryptosporidium parvum Oocyst. Environmental Research. 2000.2 Disponível em: $<$ https://www.sciencedirect.com/science/article/abs/pii/S0013935199940227?via\%3Dihub Acesso em: 26 abril. 2020.

EVANS, B. M., GRACZYK, T. K.., SHIFF, C. J., NIZEYIMANA, B., PATZ, J. A, Ecology of Zoonotic Cryptosporidiosis in Watersheds Containing Cattle Farming Operations. In: Thompson, R. C. A. et al (Eds.) Cryptosporidium: from molecules to disease. Elsevier B. V., 2003.

MATEUS, E. F. Animais à Mesa: Zoonoses e Estratégias no Consumo de Carne, 2009, 71 p. Dissertação (Mestrado em Antropologia Social e Cultural) - Universidade de Lisboa, Lisboa, PT.

\footnotetext{
${ }^{48}$ SINGER, Libertação Animal, 108-177.

${ }^{49}$ SINGER, Practical Ethics, 120.

${ }^{50}$ SINGER, Practical Ethics, 121-123.

${ }^{51}$ EIDs apud LEIBLER et al, Industrial Food Animal Production and Global Health Risks: Exploring the Ecosystems and Economics of Avian Influenza, 278. Tradução do autor: "Nearly $75 \%$ of all emerging infectious diseases (EIDs) that impact or threaten human health are zoonotic".

52 SINGER, Practical Ethics, 96. Tradução do autor: "and rights are not to be traded off against the preferences or pleasures of others".
} 
10 | Comer Animais e Zoonoses: utilidade da pecuária industrial

LEIBLER, J. H. et al. Industrial Food Animal Production and Global Health Risks: Exploring the Ecosystems and Economics of Avian Influenza. EcoHealth, 6(1): 58-70 2009. Disponível em doi: 10.1007/s10393-009-0226-0 Acesso em: 13 abril 2020.

RIVERO, Sérgio et al . Pecuária e desmatamento: uma análise das principais causas diretas do desmatamento na Amazônia. Nova econ., Belo Horizonte , v. 19, n. 1, p. 41-66, abr. 2009 Disponível em https://doi.org/10.1590/S0103-63512009000100003 Acesso em 25 abril 2020

SINGER, P. Libertação Animal. Trad. Mary Wincler. São Paulo. Editora Lugano e Editora Evolução. 2010.

SINGER, P. Practical Ethics. Second Edition. Cambridge University Press. 1993.

ZANELLA, J. Zoonoses emergentes e reemergentes e sua importância para saúde e produção animal. Pesq. agropec. bras., Brasília , v. 51, n. 5, p. 510-519, maio 2016. Disponível em: http://www.scielo.br/scielo.php?script=sci_arttext\&pid=S0100204X2016000500510\&lng=en\&nrm =iso Acesso em: 27 abril 2020. 